\title{
Choosing preclinical study models of diabetic retinopathy: key problems for consideration
}

\author{
This article was published in the following Dove Press journal: \\ Drug Design, Development and Therapy \\ 18 November 2014 \\ Number of times this article has been viewed
}

\author{
Xue-Song $\mathrm{Mi}^{1,2}$ \\ Ti-Fei Yuan ${ }^{3,4}$ \\ Yong Ding' \\ Jing-Xiang Zhong' \\ Kwok-Fai So ${ }^{4,5}$ \\ 'Department of Ophthalmology, \\ First Affiliated Hospital of Jinan \\ University, Guangzhou, Guangdong, \\ People's Republic of China; \\ ${ }^{2}$ Department of Anatomy, \\ Li Ka Shing Faculty of Medicine, \\ The University of Hong Kong, \\ Hong Kong, People's Republic \\ of China; ${ }^{3}$ School of Psychology, \\ Nanjing Normal University, \\ Nanjing, People's Republic of China; \\ ${ }^{4}$ Department of Ophthalmology, \\ Li Ka Shing Faculty of Medicine, \\ The University of Hong Kong, Hong \\ Kong; ${ }^{5}$ Guangdong-Hongkong-Macau \\ Institute of Central Nervous System, \\ Jinan University, Guangzhou, People's \\ Republic of China
}

Correspondence: Kwok-Fai So Guangdong-Hongkong-Macau Institute of Central Nervous System Regeneration, Jinan university, Huang Pu Road West 60I, Guangzhou, 510632, People's

Republic of China

Email hrmaskf@hku.hk

Jing-Xiang Zhong

Department of Ophthalmology, First Affiliated Hospital of Jinan University, Guangzhou, 510632, People's Republic of China

Email zjx85221206@163.com

\begin{abstract}
Diabetic retinopathy (DR) is the most common complication of diabetes mellitus in the eye. Although the clinical treatment for DR has already developed to a relative high level, there are still many urgent problems that need to be investigated in clinical and basic science. Currently, many in vivo animal models and in vitro culture systems have been applied to solve these problems. Many approaches have also been used to establish different DR models. However, till now, there has not been a single study model that can clearly and exactly mimic the developmental process of the human DR. Choosing the suitable model is important, not only for achieving our research goals smoothly, but also, to better match with different experimental proposals in the study. In this review, key problems for consideration in choosing study models of DR are discussed. These problems relate to clinical relevance, different approaches for establishing models, and choice of different species of animals as well as of the specific in vitro culture systems. Attending to these considerations will deepen the understanding on current study models and optimize the experimental design for the final goal of preventing DR.
\end{abstract}

Keywords: animal model, in vitro culture, ex vivo culture, neurovascular dysfunction

\section{Introduction}

The worldwide incidence of diabetes is rising quickly. Studies have shown that after 10 years of diabetes, nearly $50 \%$ of type 2 and $70 \%$ of type 1 diabetic patients will develop diabetic retinopathy (DR). ${ }^{1}$ As a leading cause of blindness in eye diseases, DR drives much attention, on the part of clinical and basic researchers, to the investigation of its mechanism and prevention. However, the pathogenesis of DR is complicated, so validated study models are needed to deepen our understanding of the disease mechanisms and for trying new approaches for early screening and therapeutic intervention.

DR is a common clinical condition. As to study models for DR, there are several different species of animal models, from tiny zebrafish to monkeys, and in vitro culture systems for retinal blood vessel assay, using human or nonhuman tissues. All of these models are aimed at mimicking the clinical course of DR, while each has its limitation in matching the full features of the human disease. Previously, there have been some reviews describing animal models of DR in great detail. ${ }^{2-6}$ In addition, there are other reviews focusing on angiogenesis models in vivo ${ }^{7}$ and in vitro. ${ }^{8}$ However, when a researcher is faced with choosing the study model for different purposes, there are many key problems to consider in advance.

In this review, a summary of the most common and important problems for consideration on the selection of appropriate study models of DR is provided. The features and challenges of clinical DR that should be considered in preclinical studies are discussed first. Then, the current research focuses in clinical and basic science are 
summarized, for researchers to consider and compare with their own experimental goals. Finally, the popular modeling approaches in common animal species, together with their advantages and limitations, are summarized. These considerations will help researchers to select the appropriate candidate when facing multiple choices of study models.

\section{Clinical considerations}

\section{Characteristics of human DR}

Clinically, DR is mainly classified in two groups, nonproliferative DR (NPDR) and proliferative DR (PDR). PDR is judged by the presence of retinal neovascularization, ${ }^{9}$ which is usually confirmed with fluorescence fundus angiography imaging. PDR is the more advanced stage of DR. In PDR, proliferating neovasculature contributes to severe complications, eg, vitreous hemorrhage, retinal scars, and tractional retinal detachment, all of which often need vitreoretinal surgery. However, the endpoint of PDR is variable, and irreversible vision loss is attributed to retinal structure damage and layer thinning. Thus, the Early Treatment of Diabetes Retinopathy Study (ETDRS) has staged NPDR with mild, moderate, and severe grades, aimed to screen risk factors and to detect the earlier stages of DR for nonsurgical treatment, eg, retinal photocoagulation or antiangiogenic therapy. ${ }^{10,11}$

Histologically, retinal vascular lesions are considered to be the hallmark and the grading criterion of DR. The first visible alteration in retinal vasculature is the formation of microaneurysms. The further changes are intraretinal focal hemorrhage, venous beading, and intraretinal microvascular abnormalities (IRMAs) showing with microvascular torsion and regional capillary nonperfusion on fluorescence fundus angiography imaging. IRMA is associated with "cotton wool" spots observed with funduscopy, which are focal infarcts of nerve fibers in essence. Following the progression of vascular damage, diabetic macular edema appears, which is one of the major causes of vision loss in DR, linking with lesions at the blood-retinal barrier. ${ }^{12,13}$

\section{Clinical challenges}

A current clinical challenge for consideration in diagnosis and prevention is the screening for risk factors that contribute to retinal vascular abnormality, for eg, studies of ocular blood flow; ${ }^{14,15}$ biomarkers detected in body fluids, like advanced glycation end products (AGEs); interleukins; and tumor necrosis factor- $\alpha(\mathrm{TNF}-\alpha) \cdot{ }^{16,17}$

As to nonsurgical therapeutic investigations, the focus has been on treating diabetic macular edema and antiangiogenesis, and on vascular cell protection to inhibit neovascularization, for eg, with vascular endothelial growth factor (VEGF) inhibitor ${ }^{18}$ or other potential ocular-delivered drugs. ${ }^{19-22}$ Recently, anti-VEGF has become one of most important discoveries to treat neovascularization clinically. However, limitations to anti-VEGF therapies also exist, eg, resistance, systemic side effects with local use, and nonVEGF-related vascular proliferative mechanisms. ${ }^{18-22}$ Indeed, other than VEGF, more and more potentially angiogenic factors have been discovered, such as insulin-like growth factor 1 (IGF-1), ${ }^{23}$ platelet-derived growth factor B (PDGF-B), erythropoietin (EPO), angiopoietin 2, ${ }^{24}$ interleukin 8 (IL-8), etc. ${ }^{25}$ Antioxidants, eg, alpha-lipoic acid (ALA), are other potential drugs that prevent micro- and macrovascular damage, by normalizing pathways downstream of mitochondrial overproduction of reactive oxygen species, and preserve pericyte coverage of retinal capillaries. ${ }^{26,27}$

As to surgical aspects, treatment advances are largely dependent on development of new instruments for the goal of perfecting results of vitreoretinal surgery. However, when DR is advanced to the proliferative stage, surgical effect is limited to the severe damage of retinal neurovascular structure. $^{28,29}$

Thus, more and more preclinical trials need to use different in vivo animal models or in vitro vascular assays to understand the mechanisms and to find potential treatment to prevent human DR.

\section{Choices of study model in DR Principle of choice: Research goal is the basic consideration}

Understanding of the mechanism of DR is complicated by the complexity of the retinal structure. The retina contains multiple cell components and structure, and when exposed to the stress of hyperglycemia, not only blood vessels but also, retinal neurons and glial cells will all be challenged by the insult. The concept of the neurovascular unit is a kind of simplified understanding of the crosstalk between the retinal blood vessel and other cells around it. ${ }^{30}$ From the view of a neurovascular hypothesis in DR, conditions of hyperglycemia induce vascular damage, thereafter destroying the microenvironment and the crosstalk between endothelial cells/pericytes and neurons, endothelial cells/pericytes and retinal glial cells, as well as neurons and glial cells, finally leading to vascular proliferation, glial proliferation, and neural degeneration (Figure 1).

Previously, the focus was on establishing various animal models of DR, and there were many classic studies 


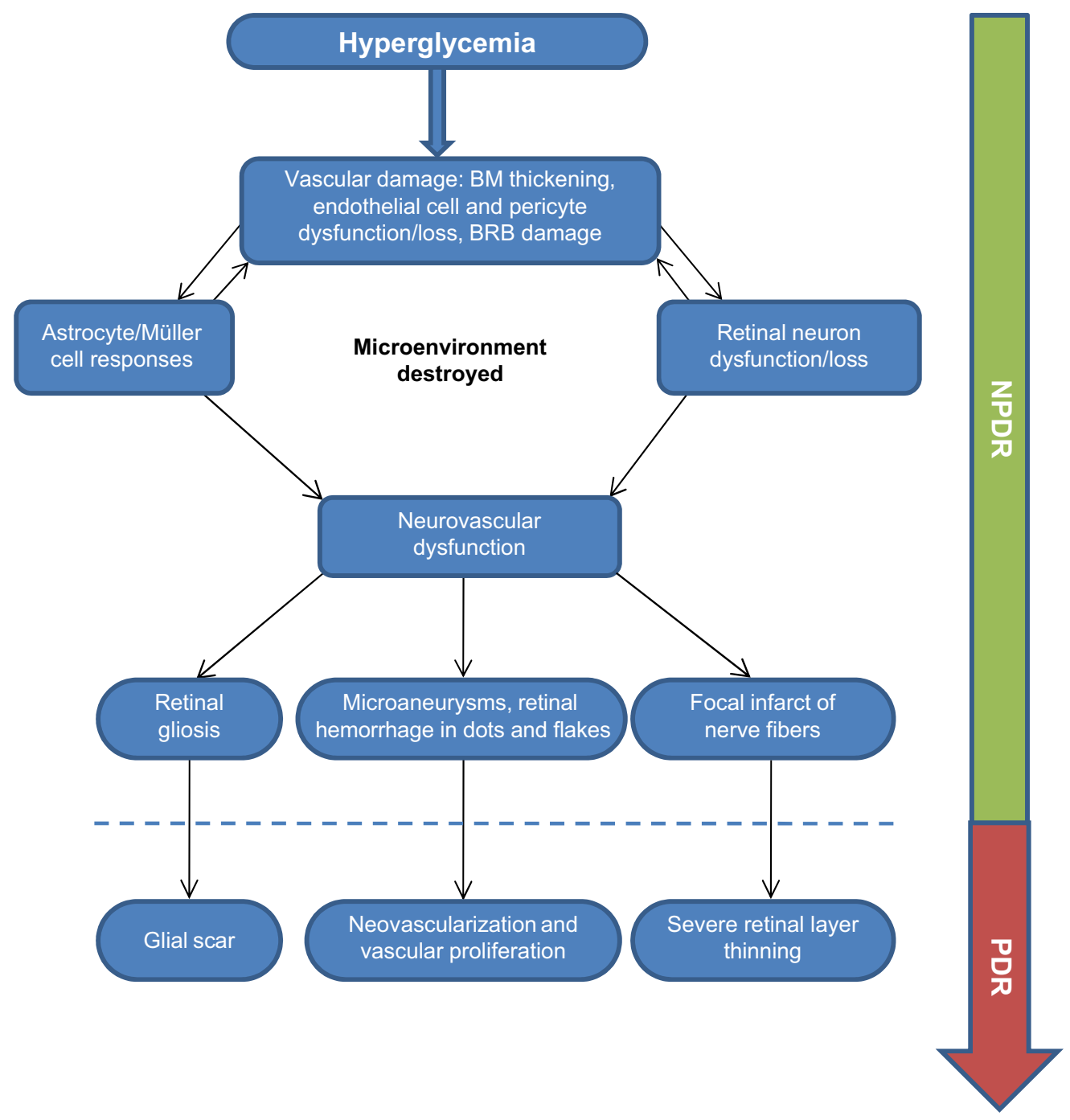

Figure I Neurovascular hypothesis for the pathogenesis of diabetic retinopathy.

Abbreviations: BM, basement membrane; BRB, blood-retinal barrier; NPDR, nonproliferative diabetic retinopathy; PDR, proliferative diabetic retinopathy.

investigating morphological damage to the retinal vasculature and comparing this to clinical features found in human DR. Studies have shown that one of the earliest histological changes of DR is thickening of the capillary basement membrane. ${ }^{31}$ Dysfunction of endothelial cells and pericytes, and thereafter cell loss, are also early phenomena, which could be responsible for the acellular capillary formation. ${ }^{4}$ It is believed that the formation of microaneurysms, the hallmark alteration of human DR, are attributed to the loss of pericytes. ${ }^{32}$ Cotton wool spots are linked with focal IRMAs. ${ }^{33}$

Therefore, we summarized the current research areas and categorized them with respect to the different stages of development of DR and according to their different goals. At different stages of NPDR and PDR, there have been different points of focus, for eg, in NPDR, the blood vessel-related research focuses on early biomarkers to detect vascular dysfunction, ${ }^{34}$ the mechanisms for how hyperglycemia induces vascular damage,,$^{35}$ and potential treatment to protect endothelial cells or pericytes from dysfunction or loss. ${ }^{22}$ Neuron-related research has focused on early detection of neural degeneration by electrophysiological methods, ${ }^{36,37}$ and neuroprotection. ${ }^{38,39}$ Glial cell-related research focuses on the response of retinal astrocytes and Müller cells. ${ }^{39}$ Microenvironment damage-related research directions include cytokines and the mechanisms of inflammation, as well as immune-associated mechanisms, etc. ${ }^{40}$ As to preventing PDR, the current research goals relate to potential therapies for inhibiting or treating the complications of neovascularization, eg, anti-VEGF, which was mentioned above. Thus, after clarifying the goal of investigation and the related stage in $\mathrm{DR}$, researchers can pay attention to the choices for different approaches and study models. 


\section{Different choices to establish study model of DR}

Currently, in the establishment of animal models for DR, there are mainly three approaches: 1 ) inducing experimental hyperglycemia, 2) using animals with spontaneous diabetes mellitus, and 3) inducing retinal angiogenesis without diabetes mellitus.

As to the approach of experimental hyperglycemia induction, this mainly includes: a) pharmacological methods, for eg, intraperitoneal injection of streptozotocin $(\mathrm{STZ})^{41-45}$ or alloxan; ${ }^{46} \mathrm{~b}$ ) diet methods, such as feeding a high-galactose diet ${ }^{46}$ and c) surgical method, for eg, Pancreatectomy. ${ }^{47}$

a) Regarding induction of pharmacological hyperglycemia, intraperitoneal injection using STZ is the classic and most popular approach to establish diabetic animal models. The mechanism is that STZ can kill pancreatic $\beta$ cells by its toxicity. Following the hyperglycemia, the animal will develop DR. Compared with the other methods listed above, STZ injection is time-saving and efficient and has been used widely in rodents and large animals, for eg, rabbits, cats, dogs, pigs, and monkeys. The standard modeling protocol that has been established in mice was suggested by the Animal Models of Diabetic Complications Consortium. ${ }^{48}$ It has been reported that the STZ-induced model could demonstrate NPDR, however, rarely forming microaneurysms. ${ }^{49}$ In addition, only a few studies reported the formation of focal neovascularization. ${ }^{50}$ Alloxan is another drug used to induce hyperglycemia. However, compared with STZ, the alloxan-induced model has needed longer time to demonstrate a milder level of pathological change of DR - reportedly 3 months in mice ${ }^{46}$ and 12 months in rats. ${ }^{51}$

b) The high galactose-diet feeding method can be used in rodents and other large animals. Compared with the STZ method, it is time-consuming. However, it is suitable for zebrafish, by just directly elevating the concentration of glucose in the fishpond..$^{52}$

c) Surgical methods, like pancreatectomy, can be used in large animals, such as cats, ${ }^{47}$ pigs, ${ }^{53}$ and monkeys. ${ }^{54}$ However, it is also time-consuming, for eg, in one report using cats, although hyperglycemia was induced quickly, within 1-2 weeks after the surgery, DR and formation of microaneurysms was observed only after around 5 years. ${ }^{47}$ Generally, experimental hyperglycemiainducted methods can be applied in wide types of animals, without obvious species limitation.

As to the approach of using spontaneously diabetic animals for study of DR, this mainly refers to use of genetic technology to create animals that develop hyperglycemia and diabetes mellitus spontaneously, followed by the development of the pathological changes of DR. The spontaneous DR model has been established using mice, rats, and zebrafish. The DR animal created under this method shares the advantage of consistent phenotypes and high successful rate of induction. However, higher cost and genetic technology are needed. In addition, compared with experimentally induced-DR methods, spontaneous diabetic animals need a longer period to demonstrate DR. There are a relatively small number of animals with special strains that can develop diabetes spontaneously, but this has been reported in rats and monkeys (Table 2). Similarly, these animals with intraspecies variation also need a longer period to demonstrate DR, while the phenotypic variation is larger than for genetically mutated animals.

As to the method of retinal angiogenesis-induction, this refers to inducing retinal blood vessel proliferation without elevation of the blood glucose. The popular methods include oxygen-induced retinopathy and VEGF ocular delivery. Currently, the oxygen-induced retinopathy method is standardized and popularly applied in mice ${ }^{55}$ and rats ${ }^{56}$ while the method of VEGF ocular delivery is more suitable for larger animals, for eg, rabbit and monkey ${ }^{57}$ Technically, these are not specific DR models, since they share phenotypes with other retinal neovascular diseases, such as retinopathy of prematurity, retinal vein occlusion, and retinal artery occlusion. However, from the view of pathogenesis, neovascularization is the same key pathogenesis in PDR. In addition, the angiogenic method can induce advanced vascular proliferation to mimic PDR, while the hyperglycemia-induced models mostly mimic NPDR. We summarized the rationale, advantages, and limitations for each popular modeling approach currently used in DR in Table 1.

\section{Animal choices in vivo and cell culture choices in vitro}

Genetically, mouse and zebrafish have the greatest potential as in vivo animal models of DR for the investigation of mechanisms and preclinical drug screening. They have advantages such as similar gene background to humans and ease of manipulation by the current genetic technology. In addition, the small size of animal is also easy to handle and house, and the short lifespan and large breeding rate can shorten the experimental period. These types of animals are inexpensive themselves, although gene modification enhances their cost. However, with the maturation of gene technology, more and more commercial gene-modified animals have already been made available for purchase for 


achieving different experimental goals with a not very high price. Detailed description of the characteristics of these genetic animals is beyond the purpose in this review; we listed the related references in Table 2. In addition, doublegene transgenic or fluorescent gene-added animals extend our understanding and deepen our investigation of the molecular nature of human diseases. These are unique advantages when compared with other animal models. ${ }^{58-62}$

Experimentally, mice and rats are still the most popular models of DR, not only because of the advantages mentioned above, but also since there have been many standardized protocols of modeling approaches available for reference to researchers, such as the STZ-injection model, oxygeninduced retinopathy model, and genetic model. In addition, rodents are suitable for the vast majority of detection reagents used in the laboratory. Monkey models share the most similar features of human DR compared with other animal models, which could be applied in research fields like live imaging examinations, diagnosing biomarker screening, and medical or surgical therapeutic trials; however, the approaches for monkeys are far from mature when compared with those for rodents. In addition, the large size, long lifespan, and inevitable ethical requirements have largely limited their applications. Other large animals, like cats and dogs, have large-sized eye balls, which are more convenient for handling than rodent eyes. However, their gene backgrounds are far from human, the number of suitable experimental reagents is far less than for rodents, and their large size needs more housing space, which all limited their usage as the choice of animal models for DR. However, compared with all the above species of animals, the zebrafish has its own advantages as a potential DR model, for eg, the experimental methods of STZ injection, ${ }^{63}$ high-glucose diet feeding, ${ }^{52}$ and hypoxia-induced retinopathy (HIR) ${ }^{64}$ are all convenient to perform in zebrafish, and the zebrafish with the gene $v h l^{-/}$mutation is a spontaneous VEGF-overexpressing animal model, which makes it suitable to mimic the development of PDR ${ }^{62}$. However, the less similar retinal vascular structure to human, difficult handling, because of tiny size, and lack of reagents for molecular studies still limit its usage.

Compared with the in vivo animal model, in vitro culture systems can be used as experimental models of retinal angiogenesis. Since pathological angiogenesis of the retina is the key cause of progression in PDR, the retinal angiogenesis assay is suitable for screening novel antiangiogenic drugs before testing in vivo animals and in patients clinically.
In this area, study about various VEGF blockers is the most important direction in recent years. Several generations have been updated, and some of them have been applied clinically to patients, for eg, pegaptanib, ranibizumab, aflibercept, and bevacizumab. ${ }^{65,66}$

Currently, there are two main kinds of in vitro culture proposals. Traditional in vitro cell culture uses isolated endothelial cells or pericytes, in particular, to maximally mimic the human angiogenic process; human-source endothelial cells and pericytes can be used more conveniently than in vivo study. Moreover, retina-derived endothelial cells can be applied ${ }^{67}$ for the search of specific inhibitors of retinal neovascularization. However, the traditional in vitro culture has its weakness since without the microenvironment of retina, isolated cells may possibly lose their responses to angiogenic molecules. Thus, another culture proposal has been created, which is the ex vivo retinal model. The ex vivo model is established with retinal culture. In PDR, isolating the retina from the in vivo DR model for culture in vitro can be useful for studying the role of proangiogenic factors or antiangiogenic factors in the development of retinal neovascularization. ${ }^{23,25,68,69}$ We summarized the popular methods applied in common modeling animals and culture systems in Table 2 .

\section{Conclusion}

The experimental model is the link between basic and clinical research. It deepens our understanding of the mechanisms and supports us in discovering novel therapeutic interventions to prevent the progression of DR. However, each DR model has its own advantages and limitations. Careful consideration in choosing the model helps us achieve the research goal with high efficiency. The preclinical modeling experiments are ultimately beneficial to clinical patients.

\section{Acknowledgments}

Our study was supported by the Natural Science Foundation of People's Republic of China 2013 (grant number 81300766), the National Program on Key Basic Research Project of China (973 Program grant number 2011CB707501), the Cultivation and Innovation Fund from Jinan University (grant number 21613311), and the Cultivation and Innovation Fund from the First Affiliated Hospital of Jinan University (grant number 2013203).

\section{Disclosure}

The authors report no conflicts of interest in this work. 


\section{References}

1. Romero-Aroca P, Sagarra-Alamo R, Basora-Gallisa J, Basora-Gallisa T, Baget-Bernaldiz M, Bautista-Perez A. Prospective comparison of two methods of screening for diabetic retinopathy by nonmydriatic fundus camera. Clin Ophthalmol. 2010;4:1481-1488.

2. Lai AK, Lo AC. Animal models of diabetic retinopathy: summary and comparison. J Diabetes Res. 2013;2013:106594.

3. Chhetri J, Jacobson G, Gueven N. Zebrafish - on the move towards ophthalmological research. Eye (Lond). 2014;28(4):367-380.

4. Chou J, Rollins S, Fawzi AA. Role of endothelial cell and pericyte dysfunction in diabetic retinopathy: review of techniques in rodent models. Adv Exp Med Biol. 2014;801:669-675.

5. Jo DH, Cho CS, Kim JH, Jun HO, Kim JH. Animal models of diabetic retinopathy: doors to investigate pathogenesis and potential therapeutics. J Biomed Sci. 2013;20:38.

6. Mirmiran P, Bahadoran Z, Azizi F. Functional foods-based diet as a novel dietary approach for management of type 2 diabetes and its complications: A review. World J Diabetes. 2014;5(3):267-281.

7. Minhas G, Morishita R, Anand A. Preclinical models to investigate retinal ischemia: advances and drawbacks. Front Neurol. 2012;3:75.

8. Rezzola S, Belleri M, Gariano G, et al. In vitro and ex vivo retina angiogenesis assays. Angiogenesis. 2014;17(3):429-442.

9. Stitt AW, Lois N, Medina RJ, Adamson P, Curtis TM. Advances in our understanding of diabetic retinopathy. Clin Sci (Lond). 2013;125(1): $1-17$.

10. Comyn O, Sivaprasad S, Peto T, et al. A randomized trial to assess functional and structural effects of ranibizumab versus laser in diabetic macular edema (the LUCIDATE study). Am J Ophthalmol. 2014;157(5):960-970.

11. Shin JY, Byeon SH, Kwon OW. Optical coherence tomography-guided selective focal laser photocoagulation: a novel laser protocol for diabetic macular edema. Graefes Arch Clin Exp Ophthalmol. Epub 2014 Jul 15.

12. Early Treatment Diabetic Retinopathy Study design and baseline patient characteristics. ETDRS report number 7. Ophthalmology. 1991; 98(5 Suppl):S741-S756.

13. Wilkinson CP, Ferris FL, Klein RE, et al; Global Diabetic Retinopathy Project Group. Proposed international clinical diabetic retinopathy and diabetic macular edema disease severity scales. Ophthalmology. 2003;110(9):1677-1682.

14. Duong TQ. Magnetic resonance imaging of the retina: from mice to men. Magn Reson Med. 2014;71(4):1526-1530.

15. Krasnicki P, Dmuchowska DA, Proniewska-Skretek E, Dobrzycki S, Mariak Z. Ocular haemodynamics in patients with type 2 diabetes and coronary artery disease. Br J Ophthalmol. 2014;98(5):675-678.

16. Mahoney SE, Loprinzi PD. Influence of flavonoid-rich fruit and vegetable intake on diabetic retinopathy and diabetes-related biomarkers. J Diabetes Complications. Epub 2014 Jun 21.

17. Murthy KR, Goel R, Subbannayya Y, et al. Proteomic analysis of human vitreous humor. Clin Proteomics. 2014;11(1):29.

18. Régnier S, Malcolm W, Allen F, Wright J, Bezlyak V. Efficacy of antiVEGF and laser photocoagulation in the treatment of visual impairment due to diabetic macular edema: a systematic review and network metaanalysis. PLoS One. 2014;9(7):e102309.

19. Bressler SB, Qin H, Melia M, et al; Diabetic Retinopathy Clinical Research Network. Exploratory analysis of the effect of intravitreal ranibizumab or triamcinolone on worsening of diabetic retinopathy in a randomized clinical trial. JAMA Ophthalmol. 2013;131(8): 1033-1040.

20. Dewan V, Lambert D, Edler J, Kymes S, Apte RS. Cost-effectiveness analysis of ranibizumab plus prompt or deferred laser or triamcinolone plus prompt laser for diabetic macular edema. Ophthalmology. 2012;119(8):1679-1684.

21. Fong AH, Lai TY. Long-term effectiveness of ranibizumab for agerelated macular degeneration and diabetic macular edema. Clin Interv Aging. 2013;8:467-483.
22. O'Neill CL, O’Doherty MT, Wilson SE, et al. Therapeutic revascularisation of ischaemic tissue: the opportunities and challenges for therapy using vascular stem/progenitor cells. Stem Cell Res Ther. 2012;3(4):31.

23. Chantelau E, Meyer-Schwickerath R, Klabe K. Downregulation of serum IGF-1 for treatment of early worsening of diabetic retinopathy: a long-term follow-up of two cases. Ophthalmologica. 2010;224(4):243-246.

24. Pfister F, Wang Y, Schreiter K, et al. Retinal overexpression of angiopoietin-2 mimics diabetic retinopathy and enhances vascular damages in hyperglycemia. Acta Diabetol. 2010;47(1):59-64.

25. Simó R, Carrasco E, García-Ramirez M, Hernández C. Angiogenic and antiangiogenic factors in proliferative diabetic retinopathy. Current Diabetes Rev. 2006;2(1):71-98.

26. Nebbioso M, Pranno F, Pescosolido N. Lipoic acid in animal models and clinical use in diabetic retinopathy. Expert Opin Pharmacother. 2013;14(13):1829-1838.

27. Nebbioso M, Federici M, Rusciano D, Evangelista M, Pescosolido N Oxidative stress in preretinopathic diabetes subjects and antioxidants. Diabetes Technol Ther. 2012;14(3):257-263.

28. Mutoh T, Kadoya K, Chikuda M. Four cases of endophthalmitis after 25-gauge pars plana vitrectomy. Clin Ophthalmol. 2012;6:1393-1397.

29. Wu L, Berrocal MH, Arévalo JF, et al. Endophthalmitis after pars plana vitrectomy: results of the Pan American Collaborative Retina Study Group. Retina. 2011;31(4):673-678.

30. Feng Y, Busch S, Gretz N, Hoffmann S, Hammes HP. Crosstalk in the retinal neurovascular unit - lessons for the diabetic retina. Exp Clin Endocrinol Diabetes. 2012;120(4):199-201.

31. Gardiner TA, Archer DB, Curtis TM, Stitt AW. Arteriolar involvement in the microvascular lesions of diabetic retinopathy: implications for pathogenesis. Microcirculation. 2007;14(1):25-38.

32. Stitt AW, Gardiner TA, Archer DB. Histological and ultrastructural investigation of retinal microaneurysm development in diabetic patients. Br J Ophthalmol. 1995;79(4):362-367.

33. Bresnick GH, Davis MD, Myers FL, de Venecia G. Clinicopathologic correlations in diabetic retinopathy. II. Clinical and histologic appearances of retinal capillary microaneurysms. Arch Ophthalmol. 1977;95(7):1215-1220.

34. Muir ER, Rentería RC, Duong TQ. Reduced ocular blood flow as an early indicator of diabetic retinopathy in a mouse model of diabetes. Invest Ophthalmol Vis Sci. 2012;53(10):6488-6494.

35. Das Evcimen N, King GL. The role of protein kinase C activation and the vascular complications of diabetes. Pharmacol Res. 2007;55(6):498-510.

36. Hori N, Komori S, Yamada H, et al. Assessment of macular function of glaucomatous eyes by multifocal electroretinograms. Doc Ophthalmol. Epub 2012 Sep 4.

37. Wright T, Cortese F, Nilsson J, Westall C. Analysis of multifocal electroretinograms from a population with type 1 diabetes using partial least squares reveals spatial and temporal distribution of changes to retinal function. Doc Ophthalmol. 2012;125(1):31-42.

38. Casini G, Dal Monte M, Fornaciari I, Filippi L, Bagnoli P. The $\beta$-adrenergic system as a possible new target for pharmacologic treatment of neovascular retinal diseases. Prog Retin Eye Res. 2014;42C:103-129.

39. Cuenca N, Fernandez-Sánchez L, Campello L, et al. Cellular responses following retinal injuries and therapeutic approaches for neurodegenerative diseases. Prog Retin Eye Res. Epub 2014 Jul 17.

40. Tang J, Kern TS. Inflammation in diabetic retinopathy. Prog Retin Eye Res. 2011;30(5):343-358.

41. Feit-Leichman RA, Kinouchi R, Takeda M, et al. Vascular damage in a mouse model of diabetic retinopathy: relation to neuronal and glial changes. Invest Ophthalmol Vis Sci. 2005;46(11):4281-4287.

42. Kumar S, Zhuo L. Longitudinal in vivo imaging of retinal gliosis in a diabetic mouse model. Exp Eye Res. 2010;91(4):530-536. 
43. Wang Z, Yadav AS, Leskova W, Harris NR. Attenuation of streptozotocin-induced microvascular changes in the mouse retina with the endothelin receptor A antagonist atrasentan. Exp Eye Res. 2010; 91(5):670-675.

44. Wang Z, Yadav AS, Leskova W, Harris NR. Inhibition of 20-HETE attenuates diabetes-induced decreases in retinal hemodynamics. Exp Eye Res. 2011;93(1):108-113.

45. Wright WS, Messina JE, Harris NR. Attenuation of diabetes-induced retinal vasoconstriction by a thromboxane receptor antagonist. Exp Eye Res. 2009;88(1):106-112.

46. Gaucher D, Chiappore JA, Pâques M, et al. Microglial changes occur without neural cell death in diabetic retinopathy. Vision Res. 2007;47(5):612-623.

47. Sennello KA, Schulman RL, Prosek R, Siegel AM. Systolic blood pressure in cats with diabetes mellitus. J Am Vet Med Assoc. 2003; 223(2):198-201.

48. Brosius FC 3rd, Alpers CE, Bottinger EP, et al; Animal Models of Diabetic Complications Consortium. Mouse models of diabetic nephropathy. J Am Soc Nephrol. 2009;20(12):2503-2512.

49. Amemiya T, Bhutto IA. Retinal vascular changes and systemic diseases: corrosion cast demonstration. Ital J Anat Embryol. 2001;106(2 Suppl 1): S237-S244.

50. Su L, Ji J, Bian J, Fu Y, Ge Y, Yuan Z. Tacrolimus (FK506) prevents early retinal neovascularization in streptozotocin-induced diabetic mice. Int Immunopharmacol. 2012;14(4):606-612.

51. Schröder S, Palinski W, Schmid-Schönbein GW. Activated monocytes and granulocytes, capillary nonperfusion, and neovascularization in diabetic retinopathy. Am J Pathol. 1991;139(1):81-100.

52. Moon TW. Glucose intolerance in teleost fish: fact or fiction? Comp Biochem Physiol B Biochem Mol Biol. 2001;129(2-3):243-249.

53. Umazume K, Barak Y, McDonald K, Liu L, Kaplan HJ, Tamiya S. Proliferative vitreoretinopathy in the Swine-a new model. Invest Ophthalmol Vis Sci. 2012;53(8):4910-4916.

54. Büchi ER, Kurosawa A, Tso MO. Retinopathy in diabetic hypertensive monkeys: a pathologic study. Graefes Arch Clin Exp Ophthalmol. 1996;234(6):388-398.

55. Vessey KA, Wilkinson-Berka JL, Fletcher EL. Characterization of retinal function and glial cell response in a mouse model of oxygeninduced retinopathy. J Comp Neurol. 2011;519(3):506-527.

56. Downie LE, Pianta MJ, Vingrys AJ, Wilkinson-Berka JL, Fletcher EL. AT1 receptor inhibition prevents astrocyte degeneration and restores vascular growth in oxygen-induced retinopathy. Glia. 2008;56(10):1076-1090.

57. Ozaki H, Hayashi H, Vinores SA, Moromizato Y, Campochiaro PA, Oshima K. Intravitreal sustained release of VEGF causes retinal neovascularization in rabbits and breakdown of the blood-retinal barrier in rabbits and primates. Exp Eye Res. 1997;64(4):505-517.

58. Han Z, Guo J, Conley SM, Naash MI. Retinal angiogenesis in the Ins2(Akita) mouse model of diabetic retinopathy. Invest Ophthalmol Vis Sci. 2013;54(1):574-584.

59. Tang L, Zhang Y, Jiang Y, et al. Dietary wolfberry ameliorates retinal structure abnormalities in $\mathrm{db} / \mathrm{db}$ mice at the early stage of diabetes. Exp Biol Med (Maywood). 2011;236(9):1051-1063.

60. Ning X, Baoyu Q, Yuzhen L, Shuli S, Reed E, Li QQ. Neuro-optic cell apoptosis and microangiopathy in KKAY mouse retina. Int J Mol Med. 2004;13(1):87-92.

61. Rakoczy EP, Ali Rahman IS, Binz N, et al. Characterization of a mouse model of hyperglycemia and retinal neovascularization. Am J Pathol. 2010;177(5):2659-2670.

62. van Rooijen E, Voest EE, Logister I, et al. von Hippel-Lindau tumor suppressor mutants faithfully model pathological hypoxia-driven angiogenesis and vascular retinopathies in zebrafish. Dis Model Mech. 2010;3(5-6):343-353.

63. Olsen AS, Sarras MP Jr, Intine RV. Limb regeneration is impaired in an adult zebrafish model of diabetes mellitus. Wound Repair Regen. 2010;18(5):532-542.
64. Cao Z, Jensen LD, Rouhi P, et al. Hypoxia-induced retinopathy model in adult zebrafish. Nat Protoc. 2010;5(12):1903-1910.

65. Semeraro F, Morescalchi F, Duse S, Gambicorti E, Romano MR, Costagliola C. Systemic thromboembolic adverse events in patients treated with intravitreal anti-VEGF drugs for neovascular agerelated macular degeneration: an overview. Expert Opin Drug Saf. 2014;13(6):785-802.

66. Stewart MW. The expanding role of vascular endothelial growth factor inhibitors in ophthalmology. Mayo Clin Proc. 2012;87(1):77-88.

67. Shima DT, Adamis AP, Ferrara N, et al. Hypoxic induction of endothelial cell growth factors in retinal cells: identification and characterization of vascular endothelial growth factor (VEGF) as the mitogen. Mol Med. 1995;1(2):182-193.

68. Haurigot V, Villacampa P, Ribera A, et al. Long-term retinal PEDF overexpression prevents neovascularization in a murine adult model of retinopathy. PLoS One. 2012;7(7):e41511.

69. Whitmire W, Al-Gayyar MM, Abdelsaid M, Yousufzai BK, El-Remessy AB. Alteration of growth factors and neuronal death in diabetic retinopathy: what we have learned so far. Mol Vis. 2011;17:300-308.

70. Kowluru RA, Tang J, Kern TS. Abnormalities of retinal metabolism in diabetes and experimental galactosemia. VII. Effect of long-term administration of antioxidants on the development of retinopathy. Diabetes. 2001;50(8):1938-1942.

71. Kador PF, Takahashi Y, Wyman M, Ferris F. Diabeteslike proliferative retinal changes in galactose-fed dogs. Arch Ophthalmol. 1995;113(3):352-354.

72. Li CR, Sun SG. VEGF expression and cell apoptosis in NOD mouse retina. Int J Ophthalmol. 2010;3(3):224-227.

73. Sima AA, Chakrabarti S, Garcia-Salinas R, Basu PK. The BB-rat an authentic model of human diabetic retinopathy. Curr Eye Res. 1985;4(10):1087-1092.

74. van Eeden PE, Tee LB, Lukehurst S, et al. Early vascular and neuronal changes in a VEGF transgenic mouse model of retinal neovascularization. Invest Ophthalmol Vis Sci. 2006;47(10):4638-4645.

75. Zhang J, Wu Y, Jin Y, et al. Intravitreal injection of erythropoietin protects both retinal vascular and neuronal cells in early diabetes. Invest Ophthalmol Vis Sci. 2008;49(2):732-742.

76. Yang YS, Danis RP, Peterson RG, Dolan PL, Wu YQ. Acarbose partially inhibits microvascular retinopathy in the Zucker Diabetic Fatty rat (ZDF/Gmi-fa). J Ocul Pharmacol Ther. 2000;16(5):471-479.

77. Lu ZY, Bhutto IA, Amemiya T. Retinal changes in Otsuka long-evans Tokushima Fatty rats (spontaneously diabetic rat) - possibility of a new experimental model for diabetic retinopathy. Jpn J Ophthalmol. 2003;47(1):28-35.

78. Miyamoto K, Ogura Y, Nishiwaki H, et al. Evaluation of retinal microcirculatory alterations in the Goto-Kakizaki rat. A spontaneous model of non-insulin-dependent diabetes. Invest Ophthalmol Vis Sci. 1996;37(5):898-905.

79. Yamada H, Yamada E, Higuchi A, Matsumura M. Retinal neovascularisation without ischaemia in the spontaneously diabetic Torii rat. Diabetologia. 2005;48(8):1663-1668.

80. Bhutto IA, Miyamura N, Amemiya T. Vascular architecture of degenerated retina in $\mathrm{WBN} / \mathrm{Kob}$ rats: corrosion cast and electron microscopic study. Ophthalmic Res. 1999;31(5):367-377.

81. Drago F, La Manna C, Emmi I, Marino A. Effects of sulfinpyrazone on retinal damage induced by experimental diabetes mellitus in rabbits. Pharmacol Res. 1998;38(2):97-100.

82. Gardiner TA, Stitt AW, Anderson HR, Archer DB. Selective loss of vascular smooth muscle cells in the retinal microcirculation of diabetic dogs. Br J Ophthalmol. 1994;78(1):54-60.

83. Lee SE, Ma W, Rattigan EM, et al. Ultrastructural features of retinal capillary basement membrane thickening in diabetic swine. Ultrastruct Pathol. 2010;34(1):35-41.

84. Yang Y, Hayden MR, Sowers S, Bagree SV, Sowers JR. Retinal redox stress and remodeling in cardiometabolic syndrome and diabetes. Oxid Med Cell Longev. 2010;3(6):392-403. 
85. Kim SY, Johnson MA, McLeod DS, et al. Retinopathy in monkeys with spontaneous type 2 diabetes. Invest Ophthalmol Vis Sci. 2004;45(12):4543-4553.

86. Papadopoulos N, Martin J, Ruan Q, et al. Binding and neutralization of vascular endothelial growth factor (VEGF) and related ligands by VEGF Trap, ranibizumab and bevacizumab. Angiogenesis. 2012;15(2):171-185.
87. Huxlin KR, Sefton AJ, Schulz M, Bennett MR. Effect of proteoglycan purified from rat superior colliculus on the survival of murine retinal ganglion cells. Brain Res Dev Brain Res. 1993;74(2):207-217.

88. Sawamiphak S, Seidel S, Essmann CL, et al. Ephrin-B2 regulates VEGFR2 function in developmental and tumour angiogenesis. Nature. 2010;465(7297):487-491.

\section{Publish your work in this journal}

Drug Design, Development and Therapy is an international, peerreviewed open-access journal that spans the spectrum of drug design and development through to clinical applications. Clinical outcomes, patient safety, and programs for the development and effective, safe, and sustained use of medicines are a feature of the journal, which has also been accepted for indexing on PubMed Central. The manuscript management system is completely online and includes a very quick and fair peer-review system, which is all easy to use. Visit http://www.dovepress.com/testimonials.php to read real quotes from published authors.

\footnotetext{
Submit your manuscript here: http://www.dovepress.com/drug-design-development-and-therapy-journal
} 